\title{
ADDRESSING PAIN AND PAIN-BASED BEHAVIOURS FOR CHILDREN AND YOUNG PEOPLE IN CHILD PROTECTION AND OUT-OF-HOME CARE
}

\section{Annette L. Jackson, Raeleen McKenzie, and Margarita Frederico}

\begin{abstract}
In this paper we discuss the concepts of physical and emotional pain and people's reactions such as pain-based behaviours. We describe our work with children and young people in the Victorian (Australia) child protection and out-ofhome care system who have experienced many painful experiences often resulting in pain-based behaviours. We describe our practice approach with a description of the "PAIN Relief" emotional first aid tool. We highlight implications for practice, and training in response to emotional pain and pain-based behaviours.
\end{abstract}

Keywords: pain-based behaviours, emotional first-aid, trauma, neuroscience

Acknowledgement: The authors acknowledge the work of Dr. Jenny Dwyer, who developed the PAIN Relief approach with the authors.

Annette Jackson MSW is Regional Director, Berry Street Gippsland, 37 Elgin Street Morwell 3840, Victoria, Australia. Email:ajackson@berrystreet.org.au

Raeleen J. McKenzie BA is a Consulting Psychologist and Clinical Neuropsychotherapist at McKenzie Psychology, Geelong, Victoria, Australia. Email: mckenziepsych8@gmail.com

Margarita Frederico MSW, MBA (corresponding author) is a Professor of Social Work and Social Policy, School of Allied Health, College of Science Health and Engineering, La Trobe University, Melbourne, Victoria. Australia. Email: M.Frederico@ latrobe.edu.au 
Pain is a universal phenomenon, yet how it is experienced and expressed is diverse. Whether it is a stiff upper lip, wailing, rocking, or grimacing in silence, the expression of pain is influenced by age, gender, cultural norms, family patterns, and the individual's historical and current context. We commonly conceptualise pain in its physical dimensions such as localisation, intensity, duration, frequency, chronicity, and type. Yet increasingly the emotional and psychological elements of pain are also being recognised. Pain is a biopsychosocial phenomenon even when its source is physical (Richardson, 2012).

In this paper we focus on the emotional and psychological pain that comes from a distressing event or cumulation of events, an experience, or an internal thought process, which may or may not be accompanied by a physical source of pain. Whilst physical pain provides a useful metaphor to better understand emotional pain, it also shares some common features with emotional pain. Pain is typically something the body seeks to alleviate as quickly as possible. The universality of pain is true for both physical and emotional pain.

Anglin's (2002) concept of pain-based behaviours drew our attention to the concept of pain as a valuable descriptor of much of what we see in the field of child protection and out-of-home care. It adds another lens to trauma-informed practice by helping to explain key messages that can otherwise be lost in obtuse terminology and jargon. It is broader than the concept of trauma. In this article we consider the concepts of pain and pain-based behaviours in our work with children and adolescents ${ }^{1}$ in the child protection and out-of-home care system in Victoria, Australia.

A construct that assists the understanding of emotional pain is that of complexity. Concepts of emotional pain, pain-based behaviours, and trauma can be difficult to engage with yet have a profound impact on the person and the situation. The high degree of complexity that exists in the lives of children in care is explored in this paper through a trauma-informed lens. An understanding of complexity facilitates working with multiple variables and rejects a linear understanding of the child's state and experiences. Understanding complexity can assist workers to make sense of the multidirectional impacts of multiple elements, such as poverty, abuse, neglect, violence, and addiction.

Another important concept, although often elusive for children in care, is love. Sadly, whilst love is part of Winnicott's (1987) "ordinary devotion", it is too often out of reach for children living in out-of-home care, especially residential care. We argue that without love being expressed by those caring for children in care, they will be left to react to pain in the only ways available to them, so pain-based behaviours will be perpetuated.

\footnotetext{
${ }^{1}$ The use of the term children throughout the paper refers to both children and adolescents unless otherwise indicated.
} 
International Journal of Child, Youth and Family Studies (2019) 10(2-3): 103-125

We discuss neuroscience principles and other theories that informed our development of an emotional first aid tool, known as "PAIN Relief" (Dwyer, Jackson, McKenzie, \& Frederico, 2010). This mnemonic tool was developed to help children be more prepared for new and potentially painful situations, and to assist workers and caregivers understand and respond to their own reactions. We describe some of the ways we apply this tool in practice.

\section{Children in Out-of-Home Care in Victoria, Australia}

The present day child protection and out-of-home care system is predicated on the realisation that some children need protection from their own parents to ensure their safety, health, and well-being. Terms such as physical abuse, sexual abuse, emotional abuse, neglect, and family violence denote countless experiences that are inadequately condensed to this concise language. This tragic reality underscores the many ways in which children in the child protection and care system commonly confront painful experiences, such as:

- Direct physical and psychological pain resulting from abuse and neglect

- Loss and grief due to separation from families or from caregivers if they experience multiple placements

- Betrayal of trust

- Absence, distortion, or inadequacy of love

- Isolation and loneliness

- Anxiety and fears of not having certainties in their future

- Resentment or shame when they become aware of how their life differs from others

- Reverberating impacts of their own behaviours leading to further harm

- Feeling deliberately silenced, misunderstood, or unworthy to be heard

- Being without control, joy, or hope

When children enter care they often arrive with few belongings but lots of emotional baggage. They bring a confused mismatch of memories, gaps in memories, reality-based and distorted thoughts, experiences of loss, and fears. Their behavioural reactions are strategies they have developed over time to help them survive their world but that may not fit their current situation. A new placement can be a source of further confusion and pain but can also provide the child with an opportunity to learn new ways to respond to the existing pain. We cannot undo or delete toxic and painful memories, but we can help make sense of them and build new positive ones. Attuned care offers children developmental experiences that support healthy emotional and relational development and new rich positive memories.

The sources of pain for children involved with child protection may stem initially from their family of origin. However, what happens to them when they enter the protection and care system may not only fail to protect them but can subject them to further harms. Court hearings, 
medical interventions, changes of residence (frequently unplanned), changes of school, changes of decisions, lack of authentic participation in decision-making, barriers to positive contact with family and friends and to building relationships, exposure to other children whose behaviours can cause pain to others, denigration and labelling in the community, and disconnection from culture and community are just some of the realities for many children in care.

A long-standing system dilemma in providing care for children is how best to provide care (especially for adolescents) when, for a range of reasons often associated with the extent of their traumatic and poor attachment history and subsequent behaviours, they are not able to be placed in foster care or kinship care. In Victoria, Australia, the policy is that residential care is for children over 12 years of age; however; residential care options for children under 12 years are also used when other alternatives do not exist. These children are sometimes placed in residential care on a short- to medium-term basis. Residential care in Victoria is usually funded by government and conducted by non-government not-for-profit community service organisations. Residential care is typically based in four-bed units located in communities that are not distinguishable from other houses in the neighbourhood.

From 2008 to 2012, the Government of the State of Victoria, Australia piloted a new form of residential care called therapeutic residential care (TRC). This was an attempt to alleviate the harmful impacts of children's experiences of trauma and to support recovery and achievement of positive life outcomes (Department of Health and Human Services, 2015) by introducing a traumafocused therapeutic approach. The pilot was successful and since 2012 approximately one quarter of residential care facilities in Victoria are TRCs. Most children in residential care, including in TRCs, are adolescents.

Therapeutic Residential Care is intensive and time-limited care for a child or young person in statutory care that responds to the complex impacts of abuse, neglect and separation from family. This is achieved through the creation of positive, safe, healing relationships and experiences informed by a sound understanding of trauma, damaged attachment, and developmental needs. (McLean, PriceRobertson, \& Robinson, 2011, p. 1)

Working within each TRC program are therapeutic specialists who are trained in understanding mental health and trauma and its impact on human development. Therapeutic specialists are professionals from disciplines such as psychology and social work. They lead the development of a therapeutic plan for each young person. The therapeutic plan guides residential care workers in understanding and responding to the child's behaviours and enhancing their general well-being. This includes educating residential care workers on pain-based behaviours and approaches to assist the young person find different ways to respond to situations that are new or are perceived as threatening. Novelty is often perceived as threatening by children who have had limited support in meeting new challenges. 
Two authors of this paper (McKenzie and Jackson), through their work in the Berry Street Take Two program (a therapeutic program for children who are clients of child protection, based within a large child and family services organisation), were part of the team that established many TRC pilots. In collaboration with Glenys Bristow of The Salvation Army WestCare, they designed and delivered the training to support the implementation of these models for all residential staff throughout Victoria. The training utilised theories of child development, trauma, and attachment to understand many aspects of the children's experiences and their path to recovery. Anglin's (2002) model was one of the major platforms informing this training. Anglin, whilst rarely using the terminology of trauma, provided fresh insight into pain-based behaviours and was very timely in informing aspects of TRC models and training, as reported in the evaluation of TRCs (VERSO Consulting Pty Ltd, 2011). A therapeutic foster care program has also been introduced in Victoria with similar principles to TRC. A significant reduction in unplanned placement changes was found to be an outcome of the foster care program (Frederico, Long, McNamara, McPherson, \& Rose, 2017). The statewide training for this therapeutic foster care program was also developed in part by McKenzie and Jackson.

\section{Pain, Trauma and Pain-Based Behaviours}

\section{Physical Pain and Reactions}

There is little surprise when someone stubs a toe and cries out and hops around or when someone is anxious and reluctant about going to the dentist. There is a natural reaction to the physical sensation of pain and a drive to avoid or alleviate that pain as quickly as possible. Nonetheless, we are puzzled when someone shows an unexpected reaction. Whether or not we interpret what we observe as an over- or under-reaction, we automatically compare their behaviour to our own lexicon of pain and pain-reactions and we judge accordingly. An elderly woman trying to explain her swollen leg to an emergency department doctor said, "I don't know what's wrong, I only know it hurts." The doctor needed to see the X-ray results and accept that her ankle was broken before acknowledging her pain as real and "worthy" of treatment and providing pain relief. X-rays are the wrong tool for seeing emotional and psychological pain. Studies using MRI and PET scans have reported structural and functional changes in the brain associated with psychological pain in the form of symptoms consistent with post-traumatic stress (Teicher \& Samson, 2016). However, such tools are unable to shed light on the depth of emotional pain.

The International Association for the Study of Pain (n.d.) defines pain as "an unpleasant sensory and emotional experience associated with actual or potential tissue damage". The painaustralia (n.d.) website adds "Pain is not just a physical sensation. It is influenced by attitudes,

beliefs, personality and social factors, and can affect emotional and mental well-being." In an article on physical pain and culture, pain is described as:

a private experience, however pain behaviour is influenced by social, cultural and psychological factors. It is these factors that influence whether private pain is 
International Journal of Child, Youth and Family Studies (2019) 10(2-3): 103-125

translated into pain behaviour, the form this behaviour takes, and the social setting in which it occurs. (Peacock \& Patel, 2008, p. 7)

Pain is not intrinsically a bad thing; in fact, it is essential. For example, it is protective and supplies a crucial signal to ward off further injury. However, chronic pain has additional elements that move it beyond just a prolonged form of "normal" pain (Twilley, 2018). This portrayal of physical pain, chronic pain, and pain-based behaviour has close symmetry with Anglin's concept of emotional or psychological pain-based behaviour.

Despite its universality, the experience of pain is often hard to put into words. There are many words we use, such as ache, hurt, sharp, dull, burning, acute, stabbing, shooting, discomfort, deep, and agony, yet they are often inadequate. We may find ourselves desperately trying to find the right way to explain a particular sensation. "Physical pain does not simply resist language but actively destroys it, bringing about an immediate reversion to a state anterior to language, to the sounds and cries a human being makes before language is learned" (Scarry, 1985, p. 4).

\section{Emotional and Physical Pain}

Emotional and psychological pain can be even more diverse and difficult to express with words, as the source of pain can be harder to perceive. We don't always know why we're crying or reacting, we can't point to the stubbed toe. We may scan our minds in vain for what has triggered this intense emotion, but there is a deeply felt pain, a physiological reaction, or strong fear nonetheless.

For the purposes of this paper, emotional and psychological pain is defined as an unpleasant sensory and emotional experience associated with actual or potential emotional or psychological harm. In his book on suicide, Shneidman (1996, p. 13) writes of psychological pain or "psychache" as "...the hurt, anguish or ache that takes hold of the mind."

In addition to each person's personal experiences of emotional pain, in communities we are increasingly exposed to displays of community-wide expressions of emotional pain through the 24-hour media and social media cycle, such as the aftermath of 9/11 and other terrorist attacks, natural disasters, children in detention, and the reality of warfare. This makes it easier to acknowledge the reality of emotional pain, but not to understand its complexities.

There is likely to be a degree of sympathy, if not empathy, for those living with ongoing physical pain due to ill-health or physical injury. Even so, compassion fatigue can lead to exasperation with sufferers of chronic physical pain. Responding with empathy can be even more challenging and frustrating when supporting those dealing with emotional pain, especially chronic emotional pain.

Society has much to learn about emotional and psychological pain and its aftermath for those living in an internally pain-filled world. Rather than emotional pain being a transitory experience, for too many children it is their only reality. Children of all ages, whose lives are 
International Journal of Child, Youth and Family Studies (2019) 10(2-3): 103-125

impacted by the traumas of physical and sexual abuse, emotional abuse, and neglect and family violence, live with such pain without understanding what it is or even that it truly exists. Similarly, children removed from their families and from all they know as familiar, even when to a safer environment, may experience this as deeply painful. There are also experiences of emotional pain such as grief from loss, fear of failure, and loneliness from isolation.

\section{Pain-Based Behaviours}

Just as children react in numerous ways to alleviate physical pain, so will they react to alleviate or in other ways deal with emotional pain. It is this reaction we call pain-based behaviours. Anglin (2002) described pain-based behaviours as a useful phrase to remind workers that challenging or concerning behaviours or emotional responses are frequently the result of triggering deep-seated and longstanding internalised pain.

Attachment behaviour is described as a child seeking proximity when in need of comfort by someone bigger, wiser, and stronger (Bowlby, 1969/1982). Pain-based behaviours are similarly adaptive in that they are a protective mechanism attempting to stop the source of pain and to alleviate the depth of painful sensations. However, as explained through trauma theory, such adaptations to mitigate pain can in turn be maladaptive and extend the child's exposure to pain.

Whatever the reaction (conscious or unconscious), the intent is usually to reduce or end the pain as quickly as possible, but not always. In some situations, a person will purposely maintain or increase physical pain to achieve a different objective, such as distraction, self-punishment, or dissociation. In other words, they may submit to physical pain in order to try to alleviate emotional pain. Just as with physical pain, it is our brain that does the work with emotional and psychological pain. Our reactions to emotional pain are similarly intended to reduce or eliminate the pain. Painbased behaviours refer to behaviours that emanate from emotional and psychological pain. As with physical pain, some reactions serve to continue the emotional pain, usually as a form of selfloathing, whereas other reactions are a means to dull or avoid the pain.

Although utilised as a protective mechanism, pain-based behaviours can continue a path that is harmful and destructive. A child can be trapped in a cycle whereby the original source of pain may be forgotten, but the consequences of the behaviours perpetuate pain anew. For this to change, those caring for them have to help break this cycle. Understanding the origins and functions of the behaviours can be helpful when working with children in out-of-home care. However, there are times when such history-taking is difficult if not impossible.

In the context of emotional and psychological pain, pain-based behaviours can erupt or develop slowly in relation to actual pain and anticipation of further pain. Pain-based behaviours can be understood as a response to each person's fundamental need for safety and how the human brain is programmed to ensure survival as its most basic function. The children we work with have lived in environments that compromised their safety, leading to the emergence of fear-based patterns of neural activation. Whether it is exposure to physical abuse, sexual abuse, emotional 
International Journal of Child, Youth and Family Studies (2019) 10(2-3): 103-125

abuse, neglect, family violence, or all of the above, children learn to adjust to a world that primes them for danger, isolation, and the absence of caring adults.

\section{Trauma}

Comparing the language of trauma with pain and pain-based behaviours highlights how trauma theory can aid understanding of the behaviours for children under duress. A useful definition of trauma developed by the Substance Abuse and Mental Health Services Administration (SAMHSA; 2014), is referred to as the three "E's":

Individual trauma results from an event, a series of events, or set of circumstances, that is experienced by an individual as physically or emotionally harmful or life threatening and that has lasting adverse effects on the individual's functioning and mental, physical, social, emotional, or spiritual well-being. (p. 6; emphasis in original)

When applying SAMHSA's definition of trauma to the concept of emotional pain, such pain may not always be directly attributable to a specific event, but it is experienced and has many effects. For the purposes of this paper, we will primarily refer to pain-based behaviours while acknowledging that it is an overlapping concept with trauma.

Children whose threat-response systems have been primed to ward off danger throughout the day and night find it difficult to approach new situations with confidence. They do not know if they will be able to avoid pain and find comfort when times are tough. Children are less able to tolerate new experiences or to seek novelty when they do not feel safe (Perry, Hambrick, \& Perry, 2015). They can be overwhelmed by old feelings of loss, helplessness, and grief that they cannot identify or label. Their behaviour is pain-based, coming from the patterns laid down in their brains responding to perceptions of threat. When children feel safe enough when facing new experiences, they can think through the situation instead of unthinkingly reacting to protect themselves.

There are numerous reasons why children in out-of-home care may respond to adults caring for them in challenging and counterproductive ways, and this includes patterns established in the brain. When children who have experienced rejection, neglect, and abuse are faced with situations that feel threatening, their brains are triggered to act defensively, and it is these defenses that lead to actions to protect themselves. As circumstances change, these behaviours may become unnecessary, but the neural circuitry continues to respond as if a threat still exists. The children become sensitised so that when they perceive a threat they can react quickly, even when the threat is not real. The brain will generate a fight, flight, or freeze response (National Scientific Council on the Developing Child, 2005; Perry, Pollard, Blakely, Baker, \& Vigilante, 1995). In the writers' experience, children who often fight or flee can generate high levels of anxiety in the broader service and legal systems that are focused on risk. This can inadvertently lead to punitive responses, changes of placement, further disruption to relationships, and reinforcing what the children are trying to avoid in the first place. For example, a child whose behaviours include 
frequently running away from placement may discover he or she is no longer allowed to return to that placement, thereby solidifying the experience of abandonment, rejection, and actual homelessness. The adolescent who uses violence to control his or her immediate environment may be placed in a youth justice custodial facility, with no control over his or her environment, thereby increasing feelings of helplessness and powerlessness. There is frequently a failure in this setting to help the adolescent manage pain-based behaviour.

To an observer, the stress experienced by children who freeze can be invisible until they place themselves in serious jeopardy, such as through self-harming. Other more subtle signs may be displayed through physical and mental health symptoms.

Before children can become aware of and change these behaviours they need to experience a safe, containing, predictable environment, enriched by rewarding relationships with safe, caring adults. Connection to safe adults can down-regulate the threat response and enable the young person to develop cortical pathways that enable them to learn.

Inconsistent, abusive, or neglectful caregiving in early childhood alters the normal development of neural systems involved in both relationships and the stress response. It is through patterned, repetitive neural stimulation provided by consistent, nurturing, predictable, responsive caregivers that the infant's brain receives what is needed to develop the capacity for healthy attachment and selfregulation capabilities. (Ludy-Dobson \& Perry, 2010, p. 30)

\section{The Brain}

Neuroscience and trauma theory offer insight into pain and pain-based behaviours. Painbased behaviours are mediated by neural circuitry that serves to ensure survival. Defensive approaches are developed when a child lives in a fearful environment with little choice over what happens to and around them (Roussow, 2014).

The human brain is equipped to live in a world of actual and potential threats. There are many interrelated systems in the sympathetic and parasympathetic nervous systems that work together to help prepare us to react to an immediate threat without "thinking", and to respond to other threats and stressors in a more "thoughtful and considered" way. For example, there is a great deal written on the role of the hypothalamus, pituitary gland, and adrenal gland (HPA) axis that is activated by the amygdala and results in increased production of neurochemicals such as norepinephrine and cortisol. These neurochemicals have different roles in preparing the body and the brain to respond quickly and efficiently to threats (e.g., National Scientific Council on the Developing Child, 2005; Nunn, 2004; Sapolsky, 2003; Shonkoff \& Phillips, 2000; van der Kolk, 2003). "The brain's neurochemistry is exquisitely sensitive to behavioral and environmental stimuli." (Shonkoff \& Phillips, 2000, p. 194). Similarly, research has shown other areas involved in the threat response include the locus coeruleus, corpus collosum, hippocampus, vagus nerve, and prefrontal cortex (Perry, 2001; Porges, 2004; Teicher \& Samson, 2016). 
International Journal of Child, Youth and Family Studies (2019) 10(2-3): 103-125

Figure 1 portrays the many facets of the brain and body implicated in the human threat response. The brain is efficient and integrated to enable survival in the face of danger.

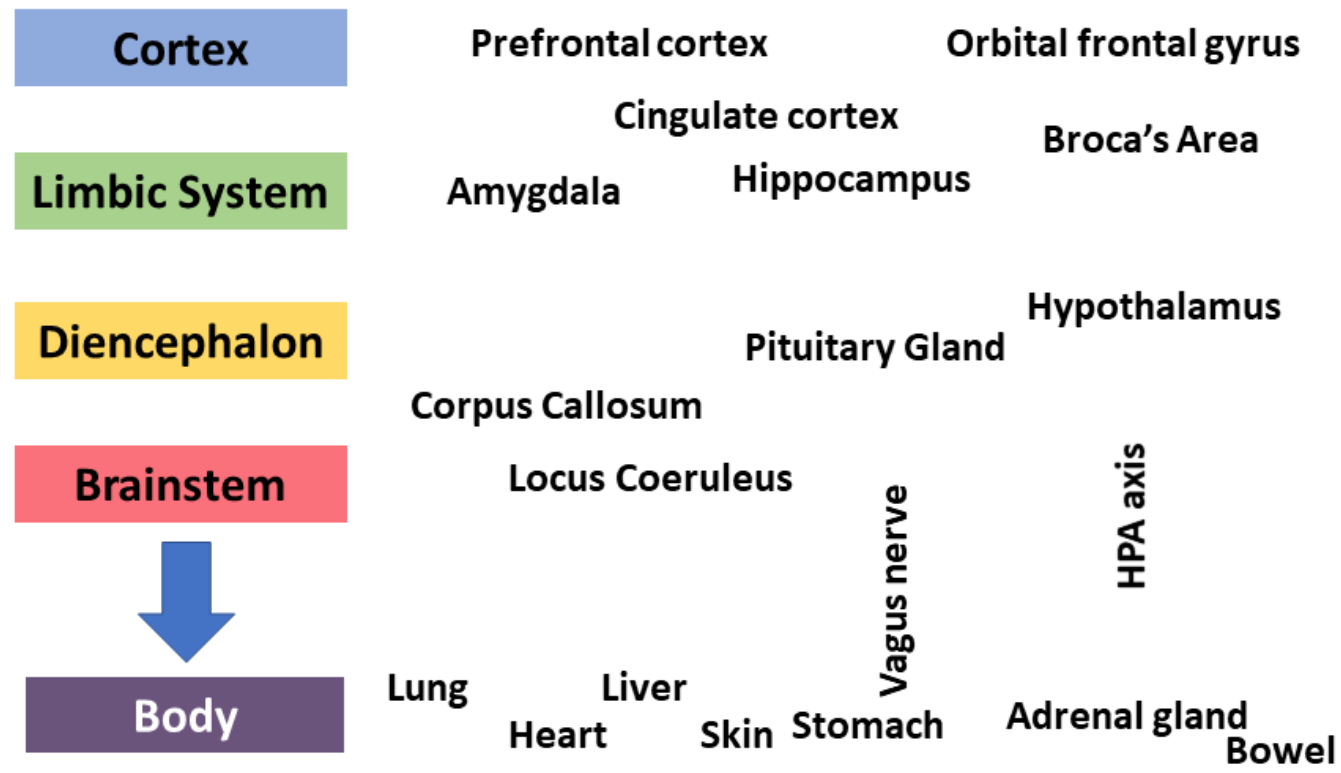

Figure 1. How the brain and body react to threat.

The Hebbian principle of neurons that fire together, wire together is commonly understood in relation to neurodevelopment (Hebb, 1949). The more often neurons fire in a similar sequence, the stronger the neural connections (synapses) become. Where children have not experienced the safety of caring adults to scaffold their development, to explain and interpret the world for them, and advise on how to respond, they must do the best they can with the limited knowledge and experience they have. In a chaotic world they use whatever defences they can to survive. If the brain pathways are consistently activated around survival mechanisms, these pathways become sensitised at the expense of other areas including the prefrontal cortex, which mediates executive function — the ability to manage thoughts, behaviours, and emotions.

Early neuroimaging studies of veterans with symptoms of PTSD showed that during the retelling of a traumatic story there was decreased functioning in Broca's area via reduction in oxygen, and increased activity in the right hemisphere. Broca's area, in the frontal cortex, is responsible for mediating word generation to match internal experience. Van der Kolk (2003) concludes it is difficult for traumatised people to speak about their experiences, especially when emotionally aroused. They often seem either too aroused or insufficiently aroused to be able to process and communicate their experiences (Hull, 2002; van der Kolk, 2003). This hearkens back to the earlier discussion about the difficulties of putting pain, especially emotional pain, into words.

Broca's area is necessary for the labelling of emotions, therefore its deactivation under symptom provocation would explain why patients with PTSD can experience 
International Journal of Child, Youth and Family Studies (2019) 10(2-3): 103-125

intense emotions without being able to label and understand them. This marries clinically with survivors often describing an inability to put their experience into words — it is, in effect, 'unspeakable'. (Hull, 2002, p. 107)

Choice or control over life circumstances along with attachment to others and the ability to avoid pain and experience pleasure are considered base elements that structure the brain optimally in the emergence of the self (Rossouw, 2014). Children in the protection and care system often have little control over much of their lives and few opportunities for the development of relationships and familiarity in a system that is driven by organisational demands, court hearings and decisions, parents who are unreliable, and changes of case managers and caregivers. All these elements are the opposite to what the young person needs. These children need familiar adults, routine, consistency, and structure to provide them with the repetition and continuity that aids their learning and embeds new behaviours into their repertoire.

An example of a neuroscientific principle relevant to how we respond to pain-based behaviours is that of state-dependent functioning. All brain-mediated functions are state-dependent (Perry et al., 1995). We not only all have some days where we are better than other days, but during our off days or off moments, such as when we are sick, tired or under threat, we do not think, feel, or behave as effectively and efficiently as at other times (Perry \& Jackson, 2018). This applies to children who may resort to more pain-based behaviours during these times, but it also applies to caregivers and workers who may struggle some days to respond in the way they would normally wish.

\section{The Essence of Relationships in Responding to Pain-Based Behaviours}

Emotional pain can only truly be resolved by and for the individual through relationship. Whilst humans of any age usually look to others when in physical or emotional pain, this is fundamental during childhood as young children are ill-equipped to deal with pain on their own. This is also true for adolescents, although their potential sources of support can be from a wider circle. Children in care have often had very disrupted relationships with their family and caregivers. As such, their ability to trust others to "kiss it better" or in other ways make the pain go away, is fragile, distorted, or non-existent. This can complicate how they learn to manage the pain in ways that caregivers, workers, and society find unacceptable or incomprehensible. It is difficult to engage at any depth with the child who views the world as hostile. Having knowledge of trauma and its consequences is important, but to respond effectively requires more than knowledge and skill.

Effective engagement leading to transformation for the young person requires the crucial element of caring about what happens to them. It is an element of care that is usually not written about, especially in the terminology of love, but is at the core of building a relationship with the children.. This type of caring in a professional relationship in social work has been referred to as agape - the Greek word for love of others. The existentialist philosopher Paul Tillich (1962) was 
one of the first to identify the importance of this concept for social work. He describes it as a concern for the well-being of others, which seeks to transform. Martin Luther King, Jr. (Washington, 2002) spoke of agape as the basis for a just society, identifying the concept as caring for one's neighbour. He described it as spontaneous, selfless, and creative, and the basis for nonviolence.

We highlight this concept of agape as working with and caring for children experiencing emotional pain can be difficult and even painful. Caregivers need to draw on their own resources and values. Having a genuine concern for the children, and wanting to find new ways to help them manage their pain, can assist in engaging with them and not rejecting them when faced with repeated difficult behaviour. The pressures on workers and caregivers when dealing with emotional pain expressed by these children can be high, and it can trigger their own pain and loss. Thus the caregiver needs to have self-awareness of the impact of their own experiences of trauma and loss. This self-awareness of how pain-based behaviours can engender feelings of helplessness, and lead to controlling responses that can trigger the pain-based behaviour of the child, can help caregivers avoid battles of escalating pain. Moreover, unrecognised feelings of pain and loss can lead to burnout for the caregiver and impact their ability to care effectively. Consideration of the needs of the children and their well-being can assist caregivers to maintain focus on the desired outcomes for the children, even when the going is tough.

\section{Complexity}

Trauma-informed practice is not and cannot be the solution to complexity. We are extraordinary and unfathomable creatures, yet we strive to discover, explore and question ourselves and our environment to try to understand our own complexity. Complexity is not a vice, but it is a challenge. (Perry \& Jackson, 2018, p. 135)

Grappling with the concept of complexity is like grappling with the ocean. We can perceive our work with children from the shallows or the depths but neither provides the whole picture. It is easy to feel overwhelmed with complexity and try to avoid it or simplify it; we may feel as if we are drowning.

In child and family welfare, the term "complex" is frequently used to describe different albeit overlapping phenomena, such as children and families with multiple problems, complicated and difficult to describe situations, high-risk children, multiple risk factors for children and families, multiple and potentially competing services involvement, and thorny dilemmas that may appear as no-win situations or situations with unforeseeable consequences and elaborate sophisticated interventions. Complexity theory places an emphasis on understanding the uniqueness of each child along with the multiple and often inter-related factors having an impact on them. Although this means we cannot prescribe a single model or intervention, we can utilise approaches that provide greater insight and assist in navigating the complexities. 
International Journal of Child, Youth and Family Studies (2019) 10(2-3): 103-125

We have defined complexity in practice as arising when children and their families have multiple and difficult problems across many domains that affect the child, family, and service system's ability to cope and respond. The customary or typical responses in these situations are likely to be insufficient. Instead, these children and their families require enhanced, integrated, flexible, and coordinated responses to redress these problems to meet the young person's needs for safety and well-being.

The study of complexity challenges notions of linear, causal, static, reductionist, and predictive approaches to knowledge and science, and yet encourages and inspires the relentless search for understanding (Carroll, 2001). Complex systems are open, multilayered, and dynamic, and can include chaotic and inexplicable behaviours as well as simple and predictable behaviours. Complexity is associated with the concept of a "system". Something that is complex comprises multiple components in an intricate arrangement that can create new or emerging properties. Complexity does not refer to something that can be explained by a single linear sequence. Thus, a complex system is a network of varied components that interact nonlinearly, to give rise to emergent and not always predictable behaviour. The brain is an example of a complex system. Neuroscience provides an important lens but cannot be sufficient to understand people or painbased behaviours.

In an article on kinship care, Warren-Adamson and Stroud (2013) noted some relevant concepts in complexity, such as attractor patterns where practices, values, and memories can perpetuate themselves over time; non-linearity; the need for caution in drawing causal conclusions; emergence as the transformational quality of complex systems; and the creative organizational phase of chaos.

Complexity relates to all humanity (Kurtz \& Snowden, 2003) not only those with painbased behaviours. All behaviour is complex, yet some behaviours are more perplexing than others. This reminds us of the need for the humility that comes with recognising that not only is pain universal but we each have our own pain-based behaviours that may catch us unawares.

Adopting a complexity perspective makes apparent enduring challenges for practice, inter alia, managing anxiety and uncertainty, sustaining continuity and containment, accruing and sustaining experience, taking account of the complex developmental needs of all the actors, and raises questions about appropriate sites for practitioners to undertake such a demanding area of child and family social work. (Warren-Adamson \& Stroud, 2013, p. 6)

\section{The PAIN Relief Emotional First Aid Approach}

The PAIN Relief approach was initially developed by the authors as an emotional first aid tool and a "circuit breaker" to assist children in residential care and youth justice who were caught in a cycle of pain-based behaviours to find new and positive ways to relate and respond. The development of the tool was informed by trauma, attachment, and human development theories; 
cognitive behavioural therapy; and solution-based practice. PAIN Relief does not aim to simplify complexity, but rather acknowledges that when dealing with complexity, we can benefit from an easy to remember mnemonic to help manage our own anxieties as well as of those we are seeking to help.

The PAIN Relief approach is not an intervention on its own. It provides workers and caregivers, regardless of whether they have professional training, with a tool to help them remember key points to help de-escalate or avoid a crisis situation, provide meaningful comfort, and model an approach from which the young person can learn. It does not take away the need for other practice interventions but it can assist the young person to be more open to these. A key message in emotional first aid approaches is a reminder to professional workers and caregivers that there needs to be an immediate response in a situation that is, or is perceived by the child to be, a threat and/or trauma.

The PAIN Relief tool guides workers and caregivers during a crisis or a perceived crisis when the child is currently safe and able to be engaged in a discussion. There are four integrated steps in the model: Predicting and Preparing; Acknowledging and putting words to feelings; Informing, and Nurturing and Noticing. There are several ways in which this tool can be used in practice. The most common way is as a mnemonic to assist workers and caregivers when wondering how they can assist children in preparation for situations they may find overwhelming and unable to manage, and therefore threatening.

Prediction and preparation reminds us that if the child perceives the unfamiliar as a threat or as an exacerbation of threat, then reducing the unknown and increasing the familiarity can contribute to the child's sense of safety and sense of control. This also applies to us as workers and caregivers. Examples of prediction in practice include providing information about what is going to occur at court, or in a medical, or in the next 30 minutes. It can also mean helping them predict how they may react to certain situations. It is not about over-preparing or crystal ball gazing but about making the "knowable known", recognising that not everything can be known. Once nebulous fears are made explicit they are less likely to be acted upon in ways that surprise or disturb the child further.

Acknowledgement: Being able to put feelings into words is one of the functions that trauma can disrupt. As stated earlier, physical and emotional pain can make finding the right words more difficult. Trauma can impact our normal ability to put words to our emotions, assuming we had the ability through normal child development in the first place. Positive emotionally informed parenting helps children learn words to describe their feelings and validates their experience. Employing this element of emotional first aid does not mean telling children what they are feeling but rather helping them find their own words.

Inform: In addition to prediction, there is often information that can assist children to manage themselves and the situations that confront them or can let them know that others are 
International Journal of Child, Youth and Family Studies (2019) 10(2-3): 103-125

managing it with them. It is important not to provide too much information but to give children control over their own information and only provide information that can assist them. For example, psychoeducation in small sound bites can help children understand why they are reacting the way they are and what choices are available for them.

Nurture and notice: We know that trauma and pain isolates and fragments. Any intervention is better when done in a relational way. Offering comfort, support, and nurture to the child in the moment can create a lifelong memory. It is not about overwhelming children with unwanted affection but finding ways to provide comfort and for them to feel that someone genuinely cares for them and notices who they are and what they are dealing with. It is perhaps in this step that the concept of agape is most useful. An emphasis on nurturing and seeking to know the children is pivotal to helping them know and like themselves.

\section{PAIN Relief in Practice}

Each of these steps can inform the development of a plan for the young person to manage emotions and predict bad feelings. It can provide a framework for an Action or Safety Plan that can be put in writing or memorised by the young person. With repetition the new thinking and behaviour can generalise to other situations and become a habit. Workers can assist the young person to identify situations that are likely to be perceived as a threat. Predicting a crisis and assisting the young person prepare a response has the potential to avert the situation being perceived as a crisis. In the preparation the young person can plan how they can regulate their behaviour and emotions. The next step of acknowledging feelings helps the young person recognise feelings that can be triggered. By labelling feelings and understanding their source they can better regulate their emotions and their response.

The PAIN Relief approach acknowledges that labelling feelings and understanding the source of the feelings can assist workers to act more effectively as we can also find these situations overwhelming. The third step, informing, is about identifying strategies that will provide alternatives to pain-based response behaviour. These strategies can inform the action plan. It also requires workers and caregivers to identify how they can respond to the child in the time of crisis. The final step in this tool, nurturing and noticing, is identifying how the adult can build a relationship with the young person. Ensuring the safety plan includes relational strategies is important so that it is not based on an illusion that safety can exist in isolation.

Emotional first aid provides a supportive framework for both the caregiver and young person. It is both protective and an early intervention. Modelling the PAIN Relief approach to children can break the cycle of pain-based behaviours and facilitate their trajectory of positive development.

The PAIN Relief approach is one way of helping the child access his or her "thinking" brain while feeling calm and therefore able to gain access to the prefrontal cortex and to learn new 
information. The PAIN Relief approach can provide a structure for understanding and responding in ways that enable choice. It begins to model to children how to think and make choices within their unique experience. Some potentially stressful events can be predicted. An aim of PAIN Relief is to offer information ahead of time so the event is not unexpected and ways of responding can be rehearsed; thus, the children will have a repertoire of helpful responses that provide choice in how they respond. This creates an increased sense of control and safety.

Of course, many stressful events are unpredictable. PAIN Relief emphasises the power of relationship at these times and the need to ensure the child is not alone in the face of the stressor. Instead, a quiet presence can help children slow their own reactivity and make sense of what is happening and consider different ways they can respond. Instead of what may have been an automatic defense reaction to protect themselves resulting in destructive behaviours, they may be able to consider alternative strategies.

PAIN Relief can also be used when providing supervision to workers or caregivers to prepare them for challenging situations. Workers in child protection, residential care, youth justice, and other aspects of the system, similar to people in all walks of life, have their own experiences of loss and trauma (Anglin, 2002). It is important for supervisors to recognise that a child's unregulated and pain-based behaviours can be perceived as threatening to workers and caregivers and they may react accordingly. Supervisors can provide a more positive environment for the children if they support workers to respond to the child's needs rather than the worker's unregulated fear. Workers can be "stuck" in their behaviour in a similar way that the child can be stuck. Anglin (2002) encourages workers and caregivers to respond rather than react, which is a parallel process to what we hope for the young person. Utilising the PAIN Relief tool, a supervisor can assist staff to move beyond their own patterned responses as well as to apply PAIN Relief in their work with the children in their care.

We have given presentations on PAIN Relief as part of the training program for TRCs, Youth Justice, and in other settings. This has enabled residential care workers, youth justice workers, and others to think ahead about how they may assist children early in the face of a threat. A recent example occurred when training a range of different professionals about sexual exploitation and different strategies to help children recover and reconnect once safety is established. PAIN Relief was provided as a mnemonic to assist workers when they were worried about "saying the right thing" to focus instead on the importance of "being with the young people" and, when the opportunities arose, using the PAIN mnemonic to structure what they wanted to discuss.

\section{An Example of PAIN Relief in Action}

Assisting a young person to manage a perceived threatening yet planned eventis described below. The case vignette demonstrates how each step in the PAIN Relief approach was used to assist a boy to gain a sense of control and identify ways to minimise the emotional pain he fears. 
International Journal of Child, Youth and Family Studies (2019) 10(2-3): 103-125

This is in contrast to an unregulated response, which could lead to an inability to avoid pain and to separate the young person from an important relationship. (Note: The name and identifying details have been changed.)

\section{Jaxon's Situation}

Jaxon was a young boy of 13 years of age living in therapeutic residential care. He had not seen his mother for 12 months. His mother suffered from serious mental health problems and drug addiction, which often made her unpredictable. Her partner, who was not Jaxon's father, had physically assaulted her and this led Jaxon to worry about her safety. He missed his mother. They had a loving relationship, but one where he felt responsible for her.

\section{The Context}

Workers were anxious about protecting Jaxon from distress should his mother either not arrive or be in a worrying state when she did, and about ensuring his emotional well-being after seeing her. They had worked hard to help him cope with the separation, and he seemed to have settled into an acceptance that his mother was responsible for her own well-being, that there were responsible adults who could assist her if she wanted help, that he would see her as soon as she was able, and that he should put energy into his own well-being.

\section{The Strategy to Address the Situation}

The PAIN Relief strategy was utilised by one of the authors of this paper in her role as a consultant therapeutic specialist, to help residential care workers manage their concerns and to help Jaxon manage his contact with his mother and to constructively deal with his emotions.

Jaxon had a history of violent, aggressive behaviour that included assaulting workers when overwhelmed and of withdrawing and disconnecting from others. In the time he had been living in therapeutic residential care, staff had worked hard to help him, with the result that his aggressive behaviour was reduced and his disengagement was significantly reduced. This was an ongoing process and took much energy as his listlessness and lack of connection would sometimes lead workers to feel sapped of energy. He had recently been much more actively engaged with others. They feared this would change.

Jaxon was very keen to see his mother but also anxious about how it would go. He had been let down many times. He had not seen his mother for a year. They had a strong bond, but she was often overwhelmed by her own circumstances and unable to prioritise him.

\section{Applying Pain Relief with Workers}

Residential care workers expressed anxiety about the proposed contact and whether it would be helpful for Jaxon. They wanted to better understand how they could support the contact and help Jaxon manage his feelings in a constructive way. We began with a discussion with the workers as a group, outlining the PAIN Relief process and rationale. 
International Journal of Child, Youth and Family Studies (2019) 10(2-3): 103-125

Predict and prepare: This phase involved speaking with workers to provide them with information on Jaxon's mother's current presentation and how the request for contact arose. This enabled them to express their fears and the type of problems they predicted might occur and to explore strategies that would be helpful. Their fears were that his mother would not arrive, and he would be disappointed, overwhelmed, and angry, which in turn might result in a worker being assaulted; his mother would arrive and not be able to live up to his expectations; or his mother would arrive drug affected and then what?

Acknowledge: The concerns were heard and acknowledged, enabling workers to discard some fears and bring others into perspective. It emerged that workers were judging Jaxon's likely reactions on the way he behaved when he first entered the therapeutic residential unit and were losing sight of the relationships they had built with him and what he had learnt about managing his feelings. While regression was possible, he also had the experience of his relationships with workers to draw on and this would be protective. There was much workers could offer him to further enable him to learn how to manage his distress.

Inform: The conversation provided the opportunity for psychoeducation to help with understanding Jaxon's likely experience and appropriate responses. Likely scenarios were posed and helpful responses identified.

Nurture and notice: It was agreed that we would meet again after the visit to discuss how each person had been able to contribute to Jaxon's responses to the situation.

\section{Applying Pain Relief with Young Person}

It was agreed that a residential care worker and the therapeutic specialist would speak to Jaxon to prepare him for his mother's visit. This would ensure that a worker he knew well was present and enabled the therapeutic specialist to model the process.

Predict and prepare: This conversation occurred with a residential care worker he knew well who could help him feel settled. A time when he was comfortable discussing the forthcoming visit from his mother was chosen.

The emphasis of this conversation was to assist Jaxon before he became distressed and overwhelmed by thinking about the different possibilities of what might occur. Questions such as how long it had been since he had seen his mother and what he thought may happen were examples. He recognised that she might not come or might be "out of it".

What if Mum didn't arrive? Why might that happen? What if she wasn't OK? He was able to say that she meant to do the right things but couldn't always manage to do it. We discussed what this meant with the aim of him understanding or reiterating that it didn't mean she didn't love him but that her problems often overwhelmed her. If she was drug affected what would he like to happen? This provided an opportunity to advise Jaxon that the worker supervising the contact might have to make that decision, but his wishes would be considered. 
International Journal of Child, Youth and Family Studies (2019) 10(2-3): 103-125

We spoke about where the visit would occur, what the setting was like, how Mum was planning to get there, how long it would be, and who would be there with him. We asked what he wanted from the worker during the visit and how he would let the worker know if he needed help.

Acknowledge: The focus here was to acknowledge and validate Jaxon's feelings of distress and abandonment without judgement.

The aim was to bring the swirling emotions and nebulous fears into consciousness and name them so they could be recognised and addressed. Jaxon had difficulty putting words to his feelings so we did this together. We talked about his mother and how things had been in the past, what his worries were, and what sensations he felt in his body when he thought about seeing her. We put words to those sensations.

We discussed how hard it is to manage these feelings and why he might be affected so deeply. We let him know that anyone would struggle with these feelings. Jaxon was asked about his worries_regarding the pending visit and we helped him to assess the impact if his fears were realised and how he could respond. The aim was to help him realise that while he might feel sad and let down, he could cope and he did not have to manage this alone.

Inform: This discussion was an opportunity to remind Jaxon about the strategies he had identified and could use when feeling uncertain of what was going to happen. Previous conversations had provided him with an opportunity to learn and practice strategies, so this focus was on tapping into information that he already held.

Nurture and notice: Following Jaxon's contact with his mother, the residential care worker and therapeutic specialist sat with Jaxon to process his feelings in a non-judgmental way that was not critical of his mother. This involved asking questions that helped him to process his feelings such as, "What was the best thing about seeing Mum?", "Was anything not so good?", and "Sometimes it's hard to say goodbye and it leaves us with sad feelings." These questions could lead into conversations at his pace. The conversation finished with thinking about how what we had discussed would be helpful with future visits; this was an opportunity for consolidation and a future orientation.

The case example presented above illustrates a way of working with children who experience emotional pain in the context of a lifetime of trauma. It also shows that the four steps in the model can be overlapping. This approach assisted the young person to take more control of his responses, recognise what he could not control about his mother, find new ways to regulate emotional pain, and build relationships that could assist in alleviating the pain. Whilst each young person and situation is unique; this approach can guide the worker and caregiver to work effectively and can give the young person their own positive strategies to approach situations perceived as threatening. 
International Journal of Child, Youth and Family Studies (2019) 10(2-3): 103-125

\section{Conclusion}

Children locked in a state of emotional pain, and who thus are driven to respond to perceived threatening situations by engaging in self-destructive behaviour, are unlikely to find new ways manage their pain without the informed support of workers and caregivers. In this paper we explored the nature of emotional pain and its impact on behaviour and relationships. We have offered an example of a practice approach to assist children, caregivers, and workers in preventing or responding to pain-based behaviours. The approach also recognises the stress on caregivers and workers when assisting the child and the value of having an easy-to-remember approach when we are desperately seeking the most helpful way to respond. 
International Journal of Child, Youth and Family Studies (2019) 10(2-3): 103-125

\section{References}

Anglin, J. P. (2002). Pain, normality, and the struggle for congruence, New York, NY: Haworth.

Bowlby, J. (1982). Attachment and loss, Vol.1: Attachment. New York, NY: Basic Books. (Original work published 1969).

Carroll, R. (2001, September). At the border between chaos and order: What psychotherapy and neuroscience have in common. Paper presented at Revolutionary Connections:

Psychotherapy and Neuroscience, the seventh professional conference of the United Kingdom Council for Psychotherapy. Retrieved from www.thinkbody.co.uk

Department of Health and Human Services. (2015). Program requirements for the delivery of therapeutic residential care in Victoria. Melbourne, Australia: Author.

Dwyer, J., Jackson, A., McKenzie, R., \& Frederico, M. (2010). Emotional PAIN relief for traumatised young people: Description of a tool for providing 'first aid plus'. International Journal of Child and Family Welfare, 1-2, 81-96.

Frederico, M., Long, M., McNamara, P., McPherson, L., \& Rose, R. (2017). Improving outcomes for children in out-of-home care: The role of therapeutic foster care. Child \& Family Social Work, 22(2), 1064-1074. doi:10.1111/cfs.12326

Hebb, D. O. (1949). The organization of behavior. New York, NY: Wiley.

Hull, A. M. (2002). Neuroimaging findings in post-traumatic stress disorder: Systematic review. British_Journal of Psychiatry, 181, 102-110. doi:10.1192/bjp.181.2.102

International Association for the Study of Pain. (n.d.). IASP terminology. Retrieved from https://www.iasp-pain.org/Education/Content.aspx?ItemNumber=1698

Kurtz, C. F., \& Snowden, D. J. (2003). The new dynamics of strategy: Sense-making in a complex and complicated world. IBM Systems Journal, 42(3), 462-483. doi: $10.1147 / \mathrm{sj} .423 .0462$

Ludy-Dobson, C., \& Perry. B. D. (2010). The role of healthy relational interactions in buffering the impact of childhood trauma. In E. Gill (Ed.), Working with children to heal interpersonal trauma: The power of play (pp. 26-43). New York, NY: Guilford.

McLean, S. Price-Robertson, R., \& Robinson, E. (2011) Therapeutic residential care in Australia: Taking stock and looking forward [National Child Protection Clearing House Issues No. 35]. Southbank, Australia: Australian Institute of Family Studies. Available at https://aifs.gov.au/cfca/publications/therapeutic-residential-care-australia-taking-stockand/definition-therapeutic 
International Journal of Child, Youth and Family Studies (2019) 10(2-3): 103-125

National Scientific Council on the Developing Child. (2005). Excessive stress disrupts the architecture of the developing brain [Working paper No. 3]. Cambridge, MA: Center for the Developing Child, Harvard University. Retrieved from https://developingchild.harvard.edu/wpcontent/uploads/2005/05/Stress_Disrupts_Architecture_Developing_Brain-1.pdf

Nunn, K. (2004). Brainwaves - The amygdala. The Clinician: Child and Adolescent Mental Health Statewide Network, 1(1-2), 46-48.

painaustralia. (n.d.). What is pain? Retrieved from https://www.painaustralia.org.au/aboutpain/what-is-pain

Peacock, S., \& Patel, S. (2008). Cultural influences on pain. Reviews in Pain, 1(2), 6-9. doi: $10.1177 / 204946370800100203$

Perry, B. D. (2001). The neurodevelopmental impact of violence in childhood. In D. Schetky \& E. P. Benedek (Eds.), Textbook of child and adolescent forensic psychiatry (pp. 221-238). Washington, DC: American Psychiatric Press.

Perry, B. D., Hambrick, E., \& Perry, R. D. (2015). A neurodevelopmental perspective and clinical challenges. In R. Fong \& R. McCoy (Eds.), Trauma related to intercountry and transracial adoptions (pp. 126-153), New York, NY: Columbia University Press.

Perry, B. D., \& Jackson, A. L. (2018). Trauma-informed leadership. In M. Frederico, M. Long, \& N. Cameron (Eds.), Leadership in child and family practice (pp. 125-141), Abingdon, UK: Routledge.

Perry, B. D., Pollard, R. A., Blakely, T. L., Baker, W. L., \& Vigilante, D. (1995). Childhood trauma, the neurobiology of adaptation and "use-dependent" development of the brain: How "states" become "traits". Infant Mental Health Journal, 16(4), 271-291. doi:10.1002/10970355(199524)16:4<271::AID-IMHJ2280160404>3.0.CO;2-B

Porges, S.W. (2004). Neuroception: A subconscious system for detecting threats and safety. Zero to Three, May, 19-24.

Richardson, G. (2012). Pain expression in different cultures: A qualitative study of the analysis for the cues of pain in different cultures [Bachelor's thesis]. Novia University of Applied Sciences, Vaasa, Finland. Retrieved from https://www.theseus.fi/bitstream/handle/10024/43628/GraceRichardson.pdf?sequence=1

Rossouw, P. J. (2014). Neuropsychotherapy: Theoretical underpinnings and clinical applications. Sydney, Australia: Mediros.

Sapolsky, R. (2003). Taming stress. Scientific American, 289(3), 86-95. doi:10.1038/scientificamerican0903-86 
International Journal of Child, Youth and Family Studies (2019) 10(2-3): 103-125

Scarry, E. (1985). The body in pain - The making and unmaking of the world. New York, NY: Oxford University Press.

Shonkoff, J. P., \& Phillips, D. A. (Eds.). (2000). From neurons to neighborhoods: The science of early childhood development. Washington, DC: National Academy Press.

Shneidman, E. S. (1996). The suicidal mind. New York, NY: Oxford University Press.

Substance Abuse and Mental Health Services Administration. (2014). SAMHSA's concept of trauma and guidance for a trauma-informed approach. Rockville, MD: Author.

Teicher, M. H., \& Samson, J. A. (2016). Annual research review: Enduring neurobiological effects of childhood abuse and neglect. Journal of Child Psychology and Psychiatry, 57(3), 241-266. doi:10.1111/jcpp.12507

Tillich, P. (1962). The philosophy of social work. Social Service Review, 36(1):13-16.

van der Kolk, B. A. (2003). Posttraumatic stress disorder and the nature of trauma, In D. J. Siegel \& M. F. Solomon (Eds.), Healing trauma: Attachment, mind, body, and brain (pp.168195). New York, NY: W. W. Norton.

VERSO Consulting Pty Ltd. (2011). Evaluation of the therapeutic residential care pilot programs: Final summary \& technical report. Clifton Hill, Australia: Department of Health and Human Services.

Warren-Adamson, C., \& Stroud, J. (2013). Using complexity theory in kinship care. Child \& Family Social Work, 20(4), 407-414. doi:10.1111/cfs.12089

Washington, J. M. (Ed.). (2002). A testament of hope: The essential writings and speeches of Martin Luther King, Jr. (2nd ed.). New York, NY: Harper Collins.

Winnicott, D. W. (1987). Babies and their mothers (C. Winnicott, R. Shepherd, \& M. Davis, Eds.). Reading, MA: Addison-Wesley. 